\title{
In the eye of the beholder? Representations of video surveillance in German public television*
}

\author{
Leon Hempel1
}

\begin{abstract}
This article is based upon an analysis of the commonalities between CCTV and television. Although this article is not meant to contribute to media studies as a science, it will nonetheless use empirical data from diverse TV shows, time periods and regions to show the decisive role television plays in public acceptance and implementation of public surveillance echnology, as well as in the construction of suspicion. Additionally, this article considers the technological similarities of CCTV and television by using TV data as a source of ethnographic material to understand the discriminating nature of visual surveillance technologies.
\end{abstract}

\section{Introduction}

Whether a phenomenon can be considered novel or not arises from the knowledge of archives. A UFA documentary film from 1939 entitled "Who drove II A 2992" tells the following story: One night, an elegant limousine left Berlin and headed at a high speed down the new Autobahn, clipping a motorcycle as it passed. The motorcyclist died; the hit-and-run driver fled the scene of the crime but left behind a door handle, which had broken off of his car. The driver stopped at a petrol station where the station attendant, noticing the missing door handle, made a note of the car model. In the meantime, the police had begun working on the case. The next day, during a live broadcast on television- and here the utopia begins - the detective came up with the idea to show the piece of evidence to the TV cameras. The station attendant, upon visiting a public TV room, recognised the handle and contacted the police, offering descriptions of both the driver and the automobile make. Both the automobile and a person matching the description of the station attendant were found in Munich. The station attendant was asked to identify the suspect via a TV connection and established that the suspect is not the driver in question. His verbal description having not been sufficient, the station attendant was then asked to give another, more

\footnotetext{
* I would like to first of all thank Hagen Boßdorf from German public television for providing me with the TV material for the following media analysis, and additionally, Aaron Leopold, Jancko Rijpma and Florian Pobbig for their help in editing this article.

1 Zentrum Technik und Gesellschaft, Technical University of Berlin, mailto:hempel@ ztg.tu-berlin.de
} 
precise, description at the police station. While in the detective's office a horse race was being broadcast- and low and behold, the station attendant recognised the hit-and-run driver on television. The detective called the station to ask the producer to direct a camera back to the man's position. The camera swung back to the bleachers, and the station attendant confirmed the identity of the driver, allowing the police via telephone communication to arrest the man.

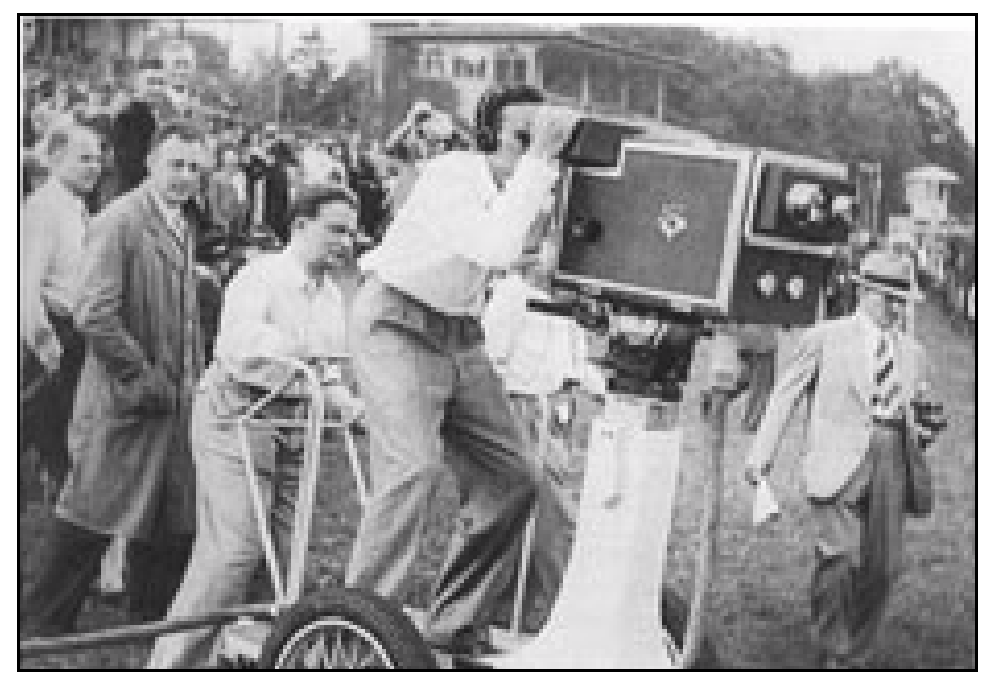

Figure 1: Still from the 1939 UFA film, Who drove II A 2992?

The message of this dramatisation is clear: modern technology is superior to oral descriptions in the battle against crime. Fallible human memory can be compensated for by a perfected technical approach. The example of the film was in no way intended to showcase a new means of fighting crime, nor was it meant to be an advertisement for an early form of camera surveillance. Instead, the point was to extol the virtues of television's public uses by giving an example that affects the public: criminality- cultural archetypes are reproduced, urban luxury is associated with criminal behaviour; the principles of work and obligation with a simple, honest nature, with the technical advantages of TV on his side. Politically speaking, it was his actions which ennobled this worker as a citizen. Indeed, the common men will come to form the major audience of TV. This new medium's justification based itself on morality - in its ability to educate society according to specific virtues - and not in its informational value. It is this public benefit which gave rise to the assumption that the use of camera technology to fight crime could be part of reason for the expansion of public television.

Both television and camera surveillance, the expansion of which we are experiencing today, are concerned with the same visual technologies; it is this technical relationship that helps these two to facilitate the propagation and popularisation of one another: the direct evidence of technically conveyed pictures is always resorted to. Whereas in 1939, the camera acted as a crime-fighting tool and popularised television, today we are experiencing just the opposite- in a world heavily socialised by television, the introduction of CCTV is being popularised through television. In contrast to television, CCTV is not considered a public medium. In fact, it is a closed system: only authorised persons have access to its control rooms. Having been separated, the ways of utilisation of television technology, TV and camera surveillance are only now finding their ways 
back towards each other in the presentation of video surveillance as well as in the fusion of entertainment and surveillance on television.

Probably the most famous example of this being the televised CCTV replay of the murder of James Bulger by two minors in a Liverpool shopping mall in February of 1993. Repeatedly broadcasted for days, the footage led to the arrest of the two perpetrators (but did not prevent the crime) and successfully convinced the British public of the need for CCTV. This combination of surveillance and television proved powerfully effective: television quite literally visualized the belief that surveillance could be a silver bullet against crime, and any further public discussion of its actual use is subjected to medial staging. In the video sequence the murder is presented simply as a forensic act, representing a qualitative milestone in which judicial violence and entertainment go hand in hand. Since pictures are no longer questioned discursively, their sole representation has become an inescapable verdict of the public as the alleged sovereign. Visual impressionability inhibits argument or further analysis, rather, the act is settled by the televisions rationale or 'logic of selection.'

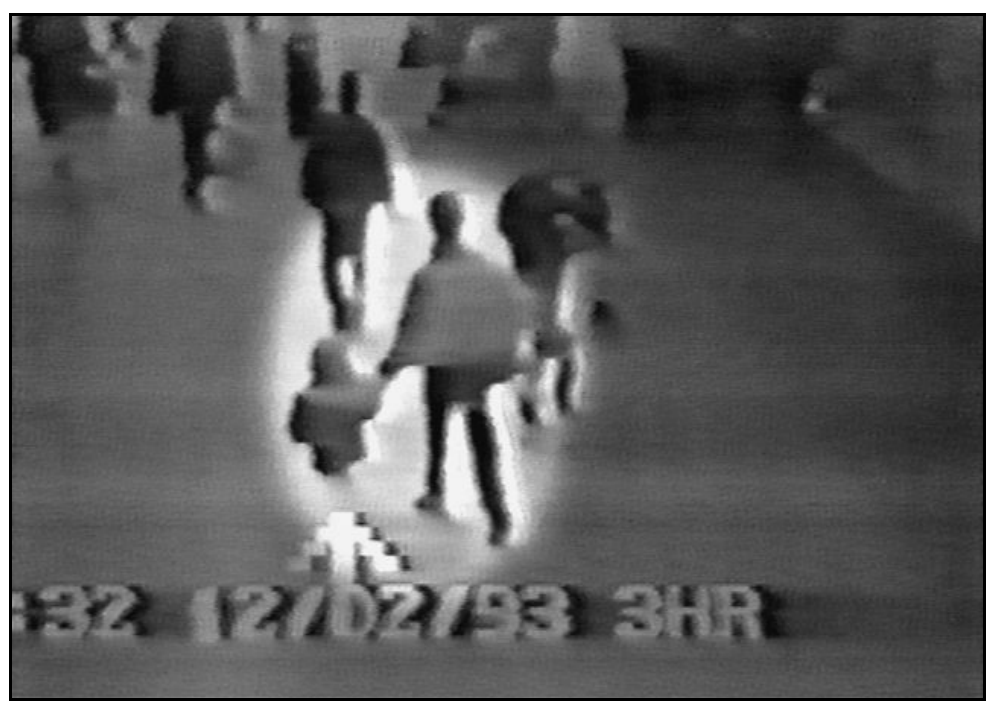

Figure 2: CCTV video footage of the abduction of J a mes Bulger

Working with texts from Foucault, Thomas Mathiesen (1997) convincingly demonstrated that the panoptic potential of surveillance, in which the few watch and control the many, and the synoptic character of the "viewer's society," which contrasts television, where the many watch the few, constitute the two sides of a complex viewing regime. Only against this background of a dual model of surveillance and watching, can we understand the astonishing acceptance of video surveillance and comprehend the disciplinary effects it can have through the recapitulation by the media of criminal deviance, and also the surveillance practices regarding the generation of suspicion. Through the principle relation of these two forms of media, the eye of the CCTV camera can, with the aid of TV, not only be conveyed self-explanatorily, but in a rehearsed manner as well. That which in 1939 seemed a dramaturgic, ideological concept, comes to mind again today- the state now recommends cooperation with the mass media in order to convince the public to introduce video surveillance and to have this in the back of their minds. A brochure published by the British Home Office stated in 1994: 
Get the local press on your side early and get a key player on your committee from the start. Ensure they realise what your objectives are, and focus them the on shopping/walking element [...] it is also useful to give a high profile to all convictions secured as a result of CCTV. Local press and TV should be constantly reminded of the numbers who plead guilty and are convicted because of the cameras.

(Home Office, 1994: 32-33, cit. Norris and Armstrong, 1999: 75)

In their book, The Maximum Surveillance Society, Clive Norris and Gary Armstrong have aptly characterized this connection as 'a perfect marriage'. Should we consider this liaison in formats other than the aforementioned British television series, one could even use the word clandestine to describe the impact of this perfect marriage. While both formats, television and CCTV, have developed their own distinct rationales in tune with their specific uses, these rationales crosstransfer between the two. This can be seen most vividly when, as a result of the rationale of television, the at-home viewer is forced into the role of observer and certain patterns of suspicion are reproduced in the unconscious mind. One finds oneself in the dispositif of CCTV, yet it is the director of the program who is simultaneously deciding who is a suspect and who is not. The director transforms the TV set into a surveillance monitor using the technological similarity between the two. To guarantee the success of this transformation, television as a mass media can constantly create the illusion that we are 'first order observers,' however, as Luhmann has stated, this is never the case, as "we are actually always looking at observations of second order... We know that this is pre-selected information, but in everyday life we do not reflect or control the selectivity of these selections and are far from being able to do so." (Luhmann, 2001: 283).

While the composition of perception for both the private viewer and the observer are the same, the private viewer remains passive, sitting in his or her armchair. Only the structural analogy of CCTV and TV in the case of video surveillance representation on television can create a rationale which enables the private viewer to take on he perspective of an observer. Without ever physically encountering the world outside, he can create one for himself through the use of a surveillance camera. The viewer can learn how to distinguish between legitimate and deviant behaviour in accordance with the cameras' gaze. The activation of the selection grid is promoted by cultural symbols in connection with particular regional milieus, as was the case in 1939. Sitting in a comfortable living room, the viewer is in a constant state of alarm, worrying and bracing himself for the rudeness of the outside world. Private viewers, like the private video watchers, can already see the things on television, which yet have to be shown on the surveillance monitor.

In the following I will justify the thesis that the viewer/observer transformation resulting in a reproduction of patterns, in a brief empirical study of representations of CCTV on German public television. Though cameras have been in use in Germany for different traffic purposes and has been preferred in the private sector for a long time, no debate about them existed until they were installed in public space. The first camera was placed in Leipzig in 1995/96 as a pilot project. According to the Berlin based political scientist Eric Töpfer, there are currently only 94 cameras operated by police in all of Germany, observing public streets and squares. This number 
does not include the cameras that are used at railway stations, parking lots or stadiums, which is estimated at about 150,000 . Theoretically, as soon as these cameras begin to represent social values, a general pubic interest in them will be created, and correspondingly, those controlling television start to care about video surveillance as well. In order to give an empirical base to this hypothesis, a study was designed which included seven national broadcasters and 17 regional broadcasters in Germany, selected according to the specific political slant of each station. Ten broadcasters were from East German/Brandenburg Broadcasting (ORB), today part of Berlin/Brandenburg Broadcasting (RBB), and seven from Bavarian Broadcasting (BR). An overview of the programmes that were used can be seen in the appendix on page 14.

In general, a state government's political position will be reflected in the alignment of regional broadcasters. However, the broadcasters' varying milieus and internal political tensions will also be visible in the shows, especially in the news and in reports. The respective political progression of CCTV in the two German states of Bavaria and Brandenburg is reflected in the examples of this study. Despite their commonalities, the selected audiovisual representations of CCTV in BR broadcasts are often void of critical comment, whereas those from the ORB are increasingly critical. Yet one should not presume that the implementation of CCTV in Bavaria occurred without criticism- the echo of criticism was simply not loudly voiced. And besides, in Germany the debate over CCTV has been promoted (as everywhere else) as a means to prevent crime and to increase feelings of safety. On the other side of the coin however, it has also been discussed as a threat in regards to a "totalitarian surveillance systems," especially in regions of former East Germany (German Democratic Republic or GDR). Concerning television, where issues are chosen according to specific ideas of presentation etc., access to the media stage is regularly denied to many intermediary actors such as smaller parties or civil rights activists (outside the leading political party, the Christian Socialist Union, CSU). Independently of whether it is critical or not, this stage is equipped with audiovisual patterns which include, for the sake of historical contrast, George Orwell's Nineteen Eighty-Four and the Stasi (secret service of the GDR). Moreover, in Bavaria the stage is dominated by the political proponents of surveillance technologies. Television proves to be a mouthpiece of politics that has adjusted to the conditions of the medium. The workings of politics withdraw to behind closed doors, reappearing in a medially prepared form with executive force. This is most notable when looking for example, at the Bavarian minister of the interior, who was able to put through video surveillance with relative ease, despite the large resistance on the communal level, because the opposition was unable to compete with the visual presence of the advocates. With this, he distinguished himself from potential competitors at both the state and federal levels simply because he was able to recommend hims elf to entire nation as a politician of strong character and will.

The considerably more complex political situation of Brandenburg necessitates making the medial platform available to more than one political course. Nonetheless, there is a recognizable preference of perception. The acrimonious public debate, particularly between the leading SPD and CDU parties, over the use of CCTV demanded the inclusion of various actors in its medial presentation. (compare: Hempel and Töpfer, 2003). This made a generally unspectacular intermediary process of negotiation amongst political decision makers visible. Broadcast news relied upon various political sources_-including parties, unions, privacy activists, policemen and 
pedestrians so as to allow viewers not only the opportunity to gain knowledge, but also to form an opinion and develop an understanding in the framework of a medial public. This produced the image of a more critical culture of communication in accordance with the ideal of public television's mission to inform and educate, particularly in contrast to their Bavarian colleagues.

A statistical comparison of allocated speaking time illustrates that in contrast to BR, the relationship of approval to criticism on ORB is reversed. The medial stage at ORB is dominated by criticism and exploited just as much as the voices of approval in southern Germany for the purposes of presenting a particular political view. It must be remembered that a critical culture of communication is just as staged as affirmative communication. The same rationale of television resides in both criticism and support of CCTV. This means that the expectations of CCTV surpass any critical objections- which is not to say that an appropriate report on CCTV does not or could not exist. Just as individual broadcasts are staged, the stubbornness of television must be broken and the customary selection choices should be made visible in the medium itself. For the purpose of a critical analysis of video surveillance, one is bound to question not the content but the form, the "how" of the selection of television itself.

After all, the medium of television draws its effective power from the illusion of representing reality in all its complexity. Due to the rationale of television, this must however be technologically adjusted, i.e. simplified. This simplification is rational and necessary in order to present an argument thoroughly and appropriately, yet it is problematic for the representation of technology. In contrast to the discourse of arguments, technology always appears as an image in medial representations - never as functioning within a multi-layered, contingent environment in which it is embedded as a social measure. On television, the specific functioning of a technical system is always more of an expectation than a fact. It is not ultimately explained how the technology works: the understanding of its functioning is left to the experts. The function of their authority is to certify the existence of a multi-layered reality. But this expertise allows no conclusions about the technology itself because it is subjected to the rationale of television as well. Their function is the legitimation of the medium. Television shapes the content to fit its form in order to distract the viewers from the simplifying functionality of the rationale. Only in this way can television create the illusion of immediacy: as an effect of entertainment which draws the viewer into the medial dimension.

The representation of CCTV technology on the $24 \mathrm{TV}$ broadcasts which were analysed illustrates how the presentation groups all aspects around their functional expectations. This is not only with regard to the representation of CCTV in the relationship of system and environment. My claim is rather that the overlapping rationales of television and CCTV will captivate the television viewer until, by the use of dramaturgical interferences, a distance between the image and viewer is created that can work against the illusionism of television.

Technology in its various components such as cameras, monitors and monitor walls, video recorders and computers dominate the imagery seen in broadcasts. Essential elements like objectives and their focal length, databases and their networking with their memory are ignored. In terms of airtime given to show the usual CCTV technology, BR with 38\%, shows more than twice that of ORB, with $18 \%$. It is assumed, independent of the context of the broadcast (e.g. 
critical or non-critical) that the inner technology works. Technology is successful when it can fulfil general expectations. If it is shown on TV, it is functioning, but barred from view in their medial representation. The single example of a broken camera appears rebellious as it breaks through the inscribed relationship of seeing and being seen at least in its symbolic value, thereby presenting a moment of resistance against the rationale of its own medium in use. However, these sorts of exceptions prove the rule. Can, on the one hand, the informational need of watching television be blamed for showing in what way cameras are mounted, and on the other hand create the impression of the omnipresence of video techniques through the accumulation of cameras in the contributions, using both the rhetorical techniques of repetition and exaggeration.

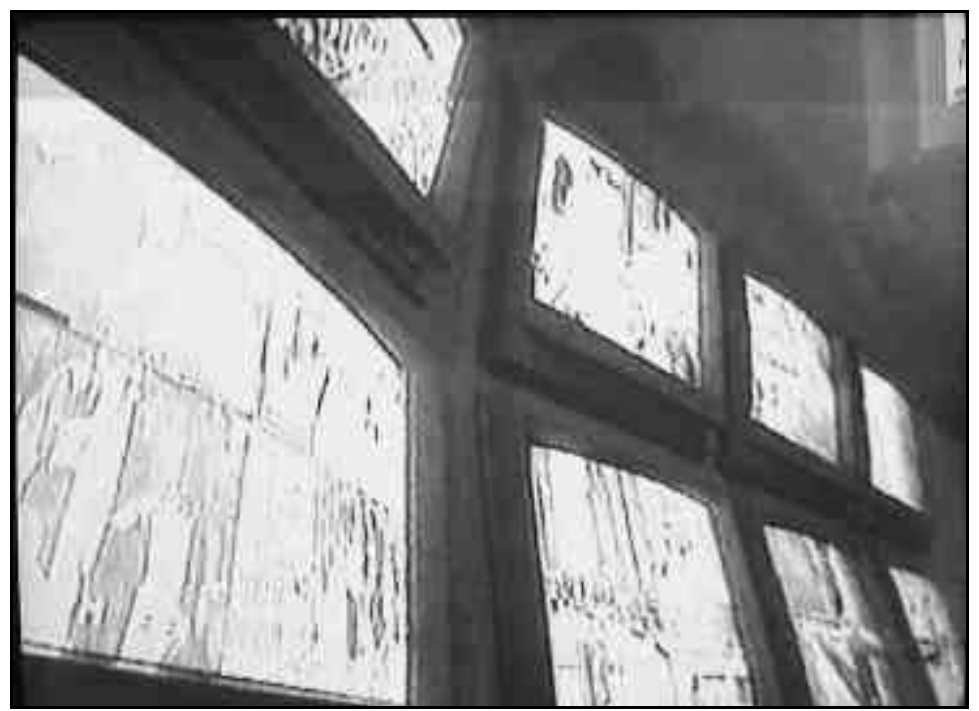

Figure 3: Typical presentation of a monitor wall (Sample 11)

This sense of omnipresence is supported significantly by television's potential effects: The typical shot of cameras is close-up and consequently, most of the cameras shown do not allow for a recognizable spatial environment, while the ergonomics of the camera shown raise the question of what the camera is watching. In most cases, nothing is said about the whereabouts of the camera either. Thus it remains unclear whether they are used and operated privately or publiclywhich could lead in turn, particularly in segments showing police observers, to the belief that the majority of cameras in public space erroneously are being taken for police CCTV. This is especially important because such a representation of CCTV ignores that the use of open street schemes are, compared to other European countries, still quite restricted. Video surveillance by the police in Germany is limited to crime 'hotspots' which must be identified beforehand by the individual German states. Moreover, in Brandenburg it has been legally prescribed that public use of CCTV must be justified by an independent evaluation before it can be put to use. 


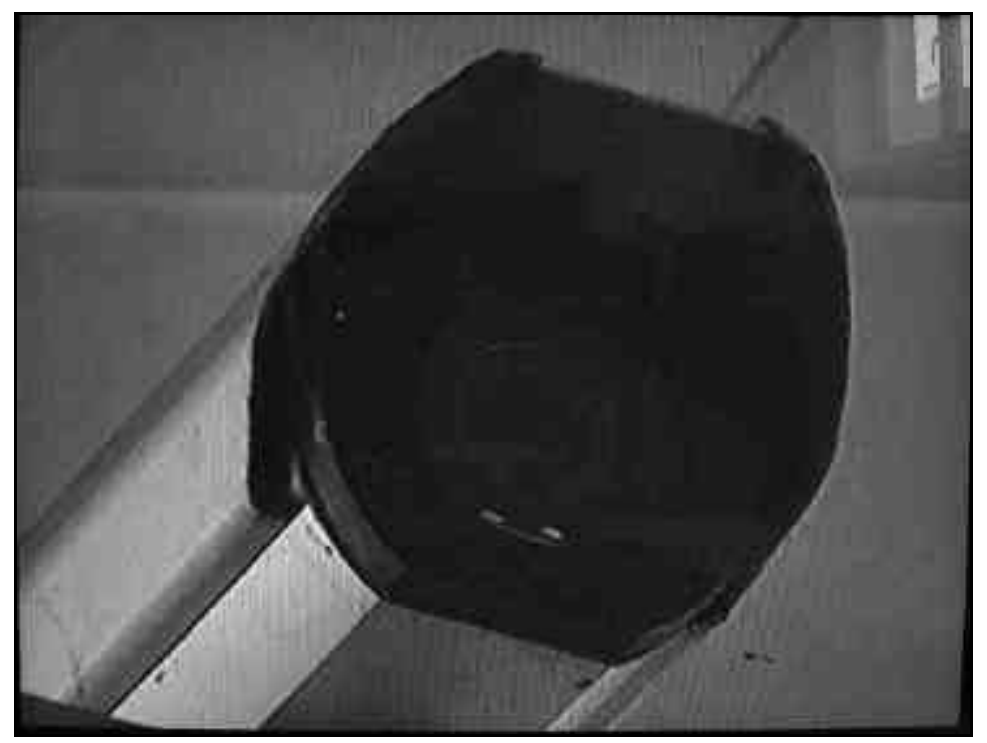

Figure 4: Typical presentation of a camera casing (Sample 16)

Another aspect has to do with the average time allotted to each shot. BR allowed less than five seconds, ORB only three seconds. The dramatic risk at this point is that, if the view of a single camera was shown for too long at a time but did not react according to the rationale of television, the viewer could get disappointed. In order to avoid any resulting doubts concerning their functionality, virtual fireworks of cameras can be found in some of the reports. In one report, 11 camera shots were shown within 9 seconds, leaving the viewer just 0.8 seconds for each.

Such an expressive effect is created through shot changes and time sequencing. It is not only the functional modes of technology which remain non-transparent here, but also the environment in which these functional modes are embedded. When different cameras are shown in quick succession, they are displaced from every time-space connection. The camera is displaced from reality to a timeless and spaceless metaphysical sphere, resulting in that which is expected of them being removed from human action, and placed rather in the form of an autonomous machine and is thus demonized. The omnipresence of cameras which, particularly in critical representations, are often linked to George Orwell's Nineteen Eighty-Four or images of the surveillance apparatus of the Stasi, creates the effect of a panoptical world. Whether or not this theatrical effect should be dismissed as hysterics or treated seriously as a form of shock therapy is up for debate. Yet in either case, the phantasmagoria of a totalitarian surveillance state is created. This is especially crucial in Germany as the historical experience of totalitarian political systems is still somewhat alive. Additionally, this presentation of technology illustrates that fear is always used in arguments here- either in terms of the threat of criminality or in terms of the threat this technology poses to the value of privacy. Both arguments follow the semantics of surveillance, should one understand this concept both in terms of protection and control. The fact that these theatrical effects serve to avert attention from the totalitarian tendency of the medial surveillance spectacle is often easily overlooked. 
The specific rationale of television prohibits a realistic assessment of technological capacity, which could hardly be seen as one of its tasks. It negates the individual case within its contextual environment for reasons of medial revaluation, which seems a legitimate approach to draw attention to relevant subjects. Yet one must bear in mind that on broadcasts, the exhibition of an assumed efficiency of technology is preferred, certified and declared. According to the medium's rationale, each social environment is subjected to a supposed technological determinism, but which in turn is subject to its own medium's rationale to communicate expectations of the technology. This determinism is seen most clearly in the representation of operators of CCTV. Without expressing their subjective views verbally, observers comprise another substratum of surveillance images in the broadcast. The interaction of different actors in a single frame of reference is not made visible here; instead it is the observer being implemented in the technical system which is being made visible: differences between machine and human appear to have been wiped away. Shown cut off from their private world, from their preferences and their needs, they merge with the technology which they operate as functional elements within the system.

The same simplification process that formed the basis of the technological development of video surveillance can therefore also be applied to the medial arrangement of broadcasts. Any emerging interferences from unexpected sources are eliminated by ignoring any kind of subjective experience. But why should this be based on television's medial rationale? Since the understanding of technology- which can be found on most of the broadcasts- assumes that it is always working according to communicated expectations. It is obvious that the observer is mainly presented as a part of this technology and not as an individual observer or as a private person. The goal of this illusion is to give the viewer the maximum feeling of authenticity possible. To achieve this, the viewer must vanish. The point of the medial rationale of television in implementing the viewer into the technical system is to involve, in the end, the viewer in the reality of the system, and to arouse his interest and keep him with the program.

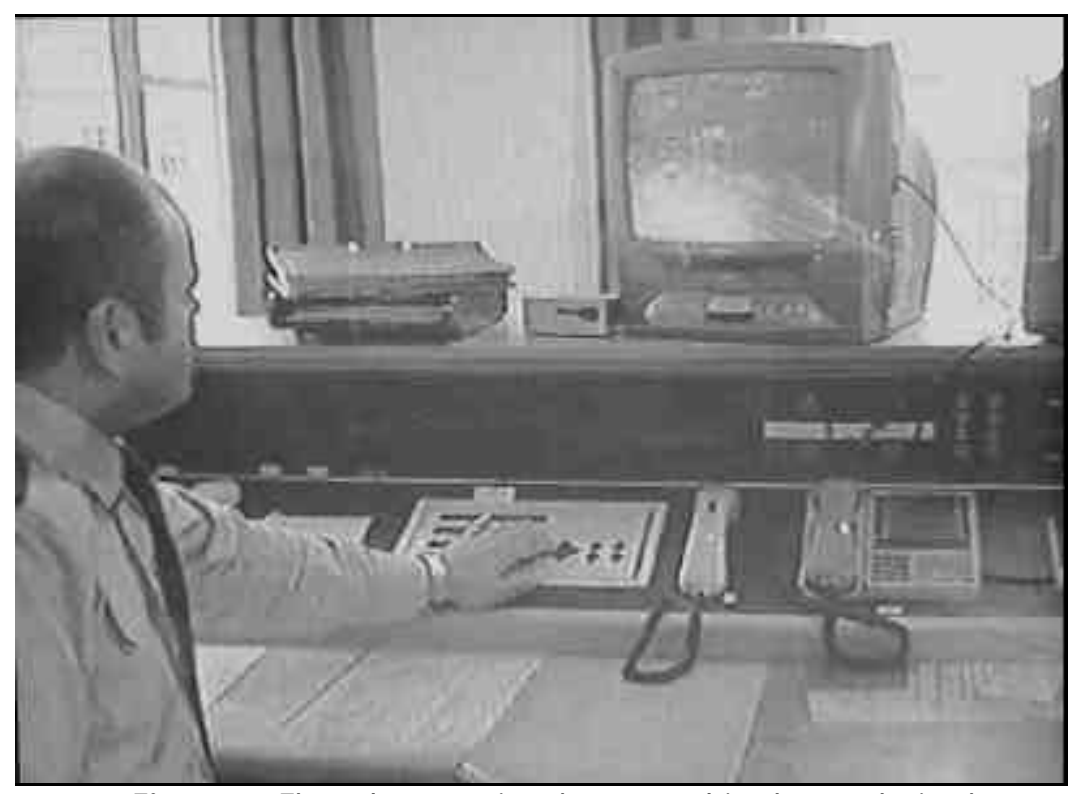

Figure 5: The observer implemented in the technical system (Sample 9) 


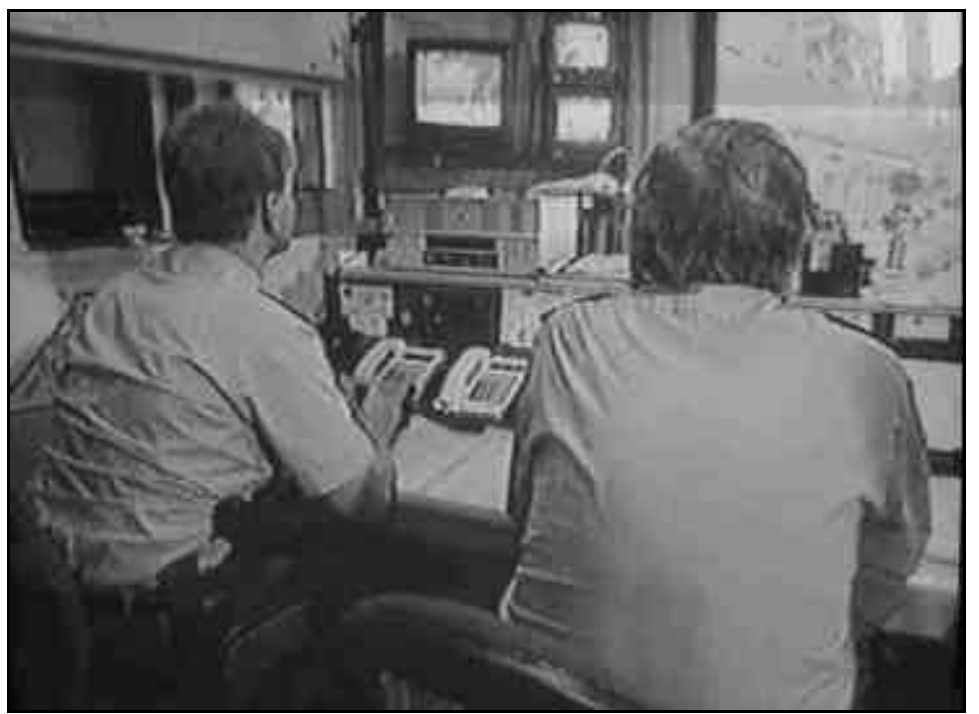

Figure 6: Observer pushed to the medial edge. (Sample 6)

The German media philosopher Knut Hickethier drew attention to the difference between a cinema and television dispositif. Unlike film, where the image is produced behind the viewer, television produces its images behind the visible screen. Thus, the television viewing public develops the sense that they are somehow connected to the "outside world" of reality. (Hickethier, 1993: 19) In contrast to an enclosed cinema theatre, the dispositive of television is always open. In a similar comparison, Vilém Flusser characterised television in 1974 as "a window to the world" while emphasizing that the viewer could only gain what is in effect a fictional impression of the 'outside world' "when the recipient excludes his knowledge of television's structure-which television itself makes easy" (Flusser, 1997: 107). The same arrangement between the television screen and the television viewer exists in the control room as well. Here too, there is an "inside" from which an "outside" can be seen. The structural similarity allows for a virtual change in position between viewer and observer in the representation of CCTV on television. As seen in one of the broadcasts, the observer is pushed to the medial edge during a camera shot to allow the viewer to more easily take his place. The viewer is reactivated out of his passive state as soon as a mugging taped by CCTV is shown, as seen in a $\mathrm{BR}$ report. The viewer slips into the role of a participating observer and is brought directly into action according to the medium's rationale of television. The visual presence of the control room fails to interfere-it is part and parcel of the armchair dispositive of television. A number of things merge simultaneously here: the observer with the technology and CCTV with television, which itself allows for the exchange of observer and viewer in this socio-technological marriage of the two uses of television technology.

In the case of the representation of CCTV in television, a particularly high level of the involvement effect can be obtained due to the close relation of both dispositives. Of course, that which is seen as the 'outside' on CCTV monitors is subordinate to television editing. The socialspatial environments shown in the broadcasts are configurations, which are the focus of medial attention. They present all types of spaces towards which the video camera could potentially be pointed instead of the television camera. In the dispositive of television, the omnipresence of 
video cameras approaches totality as when looking at the environment, the mentioning of the video camera becomes redundant. The environments presented appear not as tests influencing the functional modes of technology, but instead as enshrouding rather than shedding light upon technology. They do so by providing motifs of suspicion which the television rather than the video camera captures. Presented are neither the results of the usage nor knowledge of their impact; instead it is that which we expect of technology which is presented, albeit in a naturalistic manner with regards to the observed whose images we see.

Those observed are often shown within contexts in which they are linked to political opinions and concepts. Despite appearances, the selection of presented social-spatial environments does not provide a glimpse of the everyday functioning of CCTV. Each environment instead portrays a political stance within the debated discourse of power. Space appears highly politicized with the presentation of specific social groups. According to the double semantics of surveillance, ideally, everyone observed is subjected to both the camera's protective and controlling eye. In medial presentation however, the protective and controlling functions are separate. Criminality thus appears as a public value that is negatively constituted as a threat. This public medium par excellence reminds us of the original meaning of 'public': a structure of communication in which people interact peacefully so long as their latent violence is confined by the (violence) of the state.

The dispositively based difference between 'inside' and 'outside' is repeated by the representation of CCTV on television, presenting its own basic structure. It provides the basic grid to which, in practice, the distinction between unsuspicious/suspicious and protection/control, respectively, is added. This results in a constant to and fro within medial spaces between protected and unprotected spaces in which inside spaces are generally presented as protected and outside spaces as unprotected. The people appearing in each space are classified according to the inside/outside grid. With this classification, a whole typology of risks can be developed with which a viewer can determine what risk he will face upon entering a space if there are no cameras present. An essentially irrational statement that continuously justifies the use of CCTV is made here: the safest space is within one's own four walls, while chaos reigns outside.

Like an observer, the viewer watches the 'outside' world from the safety of his 'inside' space, except this is no longer subjected to chance, but to the rationale of television. He is located in a spatially protected position, from which he considers the 'outside' as principally unprotected. A medial grid emerges, through which a social environment can be rearranged into a new symbolic order in which the protected and controlled can be clearly differentiated. The rationale of presentation demands clear semantics here, as the social differences can be communicated only via the most unambiguous language possible. Everything associated with the body-specifically gender, age, race, social status and appearance is scrutinized for their abilities to transmit meaning on television and then put to use. Thus, because it epitomises the Christian-occidental relationship of protection, images of a mother with child on a broadcast of CCTV represent a part of the medial rationale of selection. The eye of the camera is associated with the concern of God. 


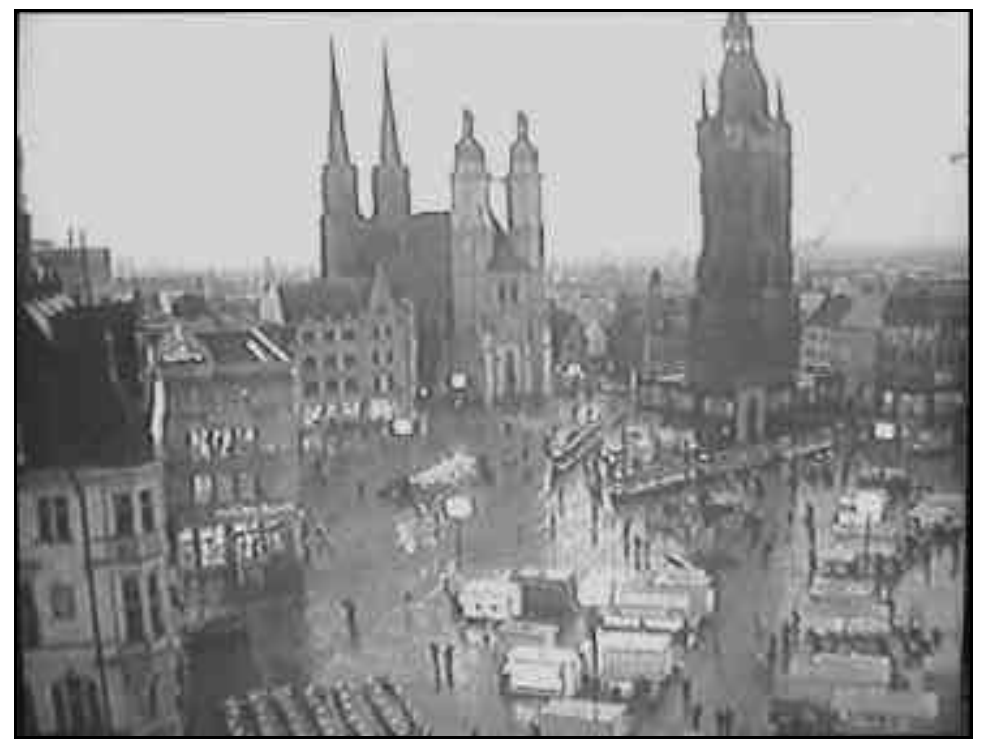

Figure 7: Appea rance sc rutinized and put to use (Sample 16)

As Nicolas Rose has illustrated, with respect to the communicated forms of control, one needs to differentiate between circles of inclusion and exclusion (Rose, 2000: 103). Such differentiation is useful particularly when considering the double function of surveillance of protection/concern and control, as Lyon suggests (2001). To a certain extent, there are two types of people being observed according to this view- those who wish to be observed for the sake of their own safety and those who are observed for the sake of others' safety. Astonishingly, the two groups can be clearly differentiated in the medial material. The dominant viewpoint for the presentation of the observed is that of an elevated perspective inserting distance between the inside and outside. This becomes the basis of a negative identification process along the lines of inclusion and exclusion that results in a medial execution. The observed appear to be rendered anonymous through the bird's eye view and thus brought into the circle of exclusion, clearly apparent to the viewer.

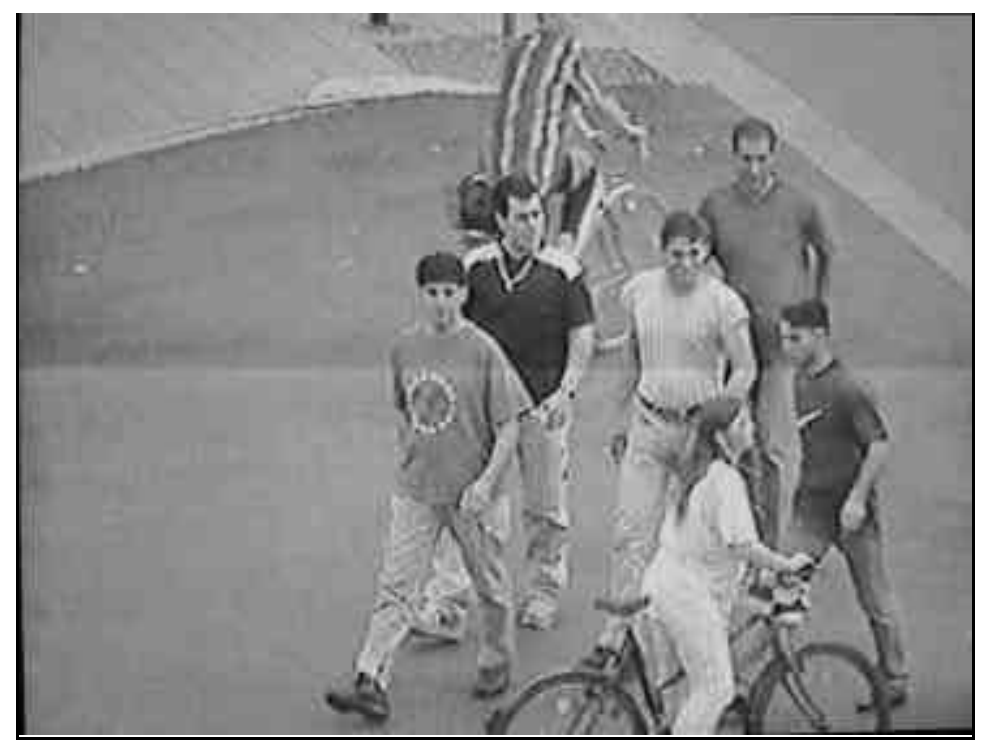

Figure 8: Anonymous through bird's eye view. (Sample 7) 
Regardless of their behaviour, the viewers at home are brought into the circle of inclusion through the camera's eye. The observed are registered in the rationale of the medial surveillance fracases while the television inescapably assigns them a seat based upon the inside/outside difference. This is underlined by a semantic contrast the above video still demonstrates. On the one side the divine eye takes control of the youngsters hanging around. At the same time the eye protects those that are typically viewed as victims; they, who pass through the outside out of necessity in order to reach the next circle of inclusion. So even if the viewer never comes into contact with the crude reality of the 'outside,' the inside' to him seems to be continually threatened by the 'outside.' This suggests that if only the position of the private snugness is exchanged with the public discomfort, it is quite possible that the acceptance and appraisal of CCTV will change again, and will be differentiated according to spatial type.

As soon as it presents video material, television appears to provide proof of the efficiency of visual surveillance measures like no other media. The sequence's evidence is doubled by the television images on our screens. This has not only to do with the images' power to suggest uninterrupted participation and create the impression that one is directly witnessing the events seen. The television as a public medium communicates not only publicity through facts, but also through selection and presentation of social and political stands. Without having to provide further peeks into the operating modes of CCTV, specific expectations concerning the functioning of a technology are authorised by the public machinery of television. In Brandenburg CCTV was introduced as a tool to combat the growing Neo-Nazism. Whether CCTV is the appropriate tool or not the marriage between CCTV and television clearly suggests this ability of the technology:

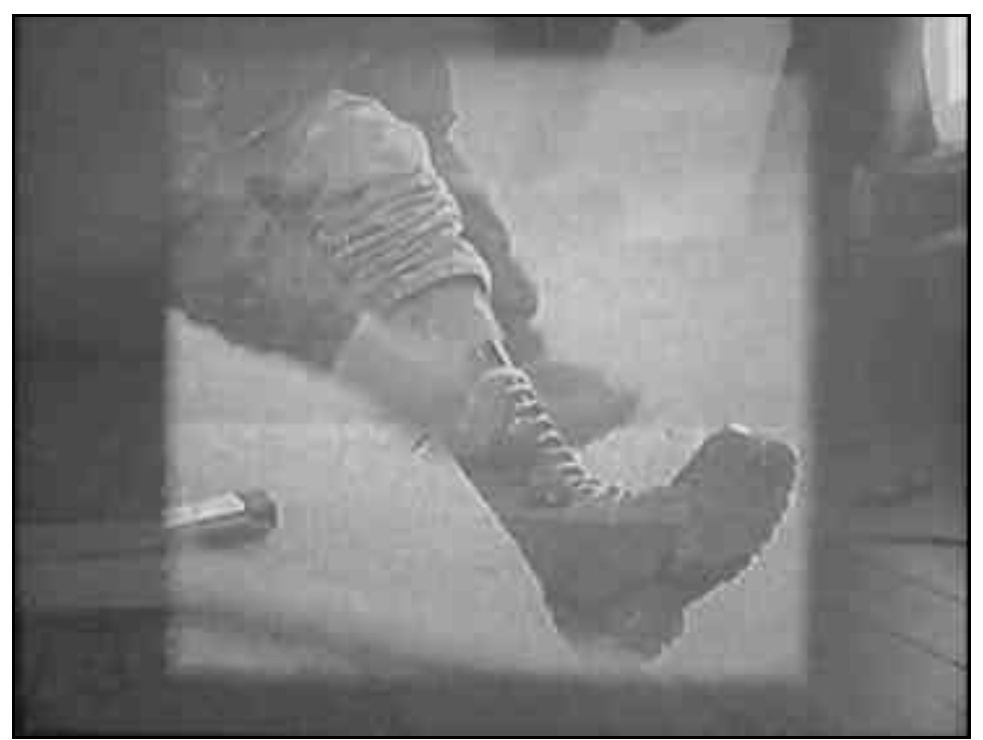

Figure 9: The crude rea lity of the 'outside' (Sa mple 21)

In Great Britain and elsewhere, the technologies of objectification have led to television 'documentary' programs using recorded video material in their appeals to participation amongst the viewing public. Whereas in the UFA film of 1939, it was the technological possibilities, and thus the offer of a classic identification, being presented to legitimate technical functions - these 
contemporary programs are limited to the replay of video sequences. Only those images selected by the rationale of television will be shown. A psychological effect is substituted for the dramaturgy: it is the promise to release the viewer from the muteness of the masses and put him into the limelight of public attention. The criminologist vision of the UFA film is thus put into practice with game show/documentary series such as Crime Beat, Eye Spy, Crimewatch or Crimestoppers. The utopia is accomplished when the video surveillance is ubiquitous. Those who successfully identify a suspect can count on the reward of appearing on television. His social awareness is rewarded with medial engagement.

\section{References}

Flusser V. (1998) Medienkultur. Frankfurt am Main:Fischer.

Hickethier,K. (2001) Film und Fernsehanalyse. Stuttgart: Metzler.

Hempel, L. and E. Töpfer (2003) 'Die Wachtürme des General a.D. Kurzsichtig in den Weiten der Mark. Gedanken zur Karriere polizeilicher Videoüberwachung in Brandenburg'. In R. Grötker (ed) Privat! Kontrollierte Freiheit in einer vernetzten Welt. Hannover: Heise, 157-166.

Luhmann, Niklas (2003) Dekonstruktion als Beobachtung zweiter Ordnung, In, Aufsätze und Reden, Stuttgart. $262-296$

Lyon, D. (2001) Surveillance Society: Monitoring Everyday Life. Buckingham: Open University Press.

Mathiesen, Thomas (1997) 'The viewer society. Michel Foucault's 'Panopticon' revisited', Theoretical Criminology 1: 215 - 234.

Norris, C. and G. Armstrong (1999) The Maximum Surveillance Society: The Rise of CCTV. Oxford: Berg. Rose, N. (2000) 'Tod des Sozialen. Eine Neubestimmung der Grenzen des Regierens. Gouvernementalité der Gegenwart'. In U. Bröckling, S. Krasmann and T. Lemke (eds.) Studien zur Ökonomisierung des Sozialen. Frankfurt am Main: Suhrkamp, 72-109.

\section{Pictures}

Picture 1:

Museumsstiftung Post und Telekommunikation, „,Wer fuhr II A 2992?“ Ufa (A uftraggeber / Institution) 1939 http://www.museumsstiftung.de/stiftung/d1xx_sammlungen.asp?dbid=11\&kattype=C\&kat=167

last visited 28/07/2005

Picture 2:

Video still of the broadcast on British television in February 1993, recorded by Jamie Wagg.

"Photographesomenon", Winfried Pauleit in "Bild - Raum - Kontrolle", Hempel and Metelmann, 2005.

Other pictures:

Video stills from the television samples used in this study. The sample numbers refer to the numbers in the appendix. 


\section{Appendix 1: Television programmes analyzed}

\begin{tabular}{|c|c|c|c|c|c|c|c|c|}
\hline \multicolumn{9}{|c|}{ National } \\
\hline No. & Title & $\begin{array}{l}\text { Format of the } \\
\text { broadcast }\end{array}$ & Program title & Network & Date & Time & \begin{tabular}{|l} 
Duratio \\
n
\end{tabular} & Video \\
\hline 1 & Vü in Bayem & Daily news & Politik Aktuell & & 3.8 .01 & & $3: 00$ & $0: 34: 14$ \\
\hline 2 & $\begin{array}{l}\text { VÜ in } \\
\text { Deutschland: } \\
\text { La uert der große } \\
\text { Bruder bald } \\
\text { überall? }\end{array}$ & $\begin{array}{l}\text { Political } \\
\text { report (twice } \\
\text { a month) }\end{array}$ & Kontra ste & $\begin{array}{l}\text { ARD } \\
\text { /SFB }\end{array}$ & 13.1 .00 & $21: 00$ & 9:10 & $0: 24: 58$ \\
\hline 3 & $\begin{array}{l}\text { VÜ: Erfa hrungen } \\
\text { aus dem Osten }\end{array}$ & Daily news & Tagesthemen & $\begin{array}{l}\text { ARD } \\
\text { / MDR }\end{array}$ & 14.3 .00 & $22: 31$ & $2: 18$ & $0: 20: 15$ \\
\hline 4 & $\begin{array}{l}\text { Großer Bruder - } \\
\text { Vü }\end{array}$ & \begin{tabular}{l|} 
Scientific \\
report \\
(weekly) \\
\end{tabular} & Nano & SWR & 29.3 .00 & $?$ & $5: 03$ & $0: 37: 29$ \\
\hline 5 & VÜ in Schulbussen & $\begin{array}{l}\text { Daily } \\
\text { news(täglich) }\end{array}$ & \begin{tabular}{|l} 
Nachtmagazi \\
$\mathrm{n}$
\end{tabular} & $\begin{array}{l}\text { ARD } \\
\text { /ORB } \\
\end{array}$ & 6.4 .00 & $1: 15$ & $2: 10$ & $0: 22: 34$ \\
\hline 6 & Rent a Big Brother & \begin{tabular}{|l|} 
Pop-Culture \\
news (daily) \\
\end{tabular} & Brisant & \begin{tabular}{|l|} 
ARD \\
$/$ MDR \\
\end{tabular} & 11.4 .01 & \begin{tabular}{|l|}
$17: 14 /$ \\
$18: 22$ \\
\end{tabular} & $2: 45$ & $0: 17: 26$ \\
\hline 7 & $\begin{array}{l}\text { Alles unter } \\
\text { Kontrolle? } \\
\text { Ausblick auf eine } \\
\text { videoüberwachte } \\
\text { Gesellschaft }\end{array}$ & $\begin{array}{l}\text { Themed } \\
\text { report }\end{array}$ & & & & & & $\begin{array}{l}2 . \\
\text { Band }\end{array}$ \\
\hline
\end{tabular}

\section{Brandenburg}

\begin{tabular}{|l|l|l|l|l|l|l|l|l|}
\hline No. & \multicolumn{1}{|c|}{ Title } & $\begin{array}{c}\text { Format of the } \\
\text { broadcast }\end{array}$ & Program title & Network & Date & Time & $\begin{array}{l}\text { Duratio } \\
\mathbf{n}\end{array}$ & Video \\
\hline 8 & $\begin{array}{l}\text { Vandalismus in } \\
\text { Straßenbahnen }\end{array}$ & Daily news & $\begin{array}{l}\text { Brandenburg } \\
\text { Aktuell }\end{array}$ & ORB & 6.11 .97 & $21: 30$ & $2: 15$ & $0: 42: 40$ \\
\hline 9 & $\begin{array}{l}\text { Videoüberwachter } \\
\text { Spielplatz }\end{array}$ & Daily reports & Abendjoumal & ORB & 25.8 .98 & $19: 00$ & $2: 57$ & $0: 56: 51$ \\
\hline 10 & $\begin{array}{l}\text { Polizeireform in } \\
\text { Brandenburg }\end{array}$ & Daily news & $\begin{array}{l}\text { Brandenburg } \\
\text { Aktuell }\end{array}$ & ORB & 16.2 .00 & $21: 30$ & $1: 39$ & $0: 44: 57$ \\
\hline 11 & $\begin{array}{l}\text { Videoüberwachung in } \\
\text { Brandenburg }\end{array}$ & $\begin{array}{l}\text { Politic al } \\
\text { Report(weekly) }\end{array}$ & Die Woche & ORB & 18.2 .00 & $19: 50$ & $3: 30$ & $0: 46: 43$ \\
\hline 12 & Der Video-Bus & Da ily news & $\begin{array}{l}\text { Brandenburg } \\
\text { Aktuell } \\
\text { Brandenburg } \\
\text { Aktuell }\end{array}$ & ORB & 5.4 .00 & $19: 30$ & $2: 13$ & $0: 50: 03$ \\
13 & Videoüberwachung & Daily news & 3.8 .00 & $19: 30$ & $2: 25$ & $0: 52: 14$ \\
\hline 14 & Videoüberwachung & Daily news & $\begin{array}{l}\text { Brandenburg } \\
\text { Aktuell }\end{array}$ & ORB & 9.8 .00 & $19: 30$ & $2: 15$ & $0: 54: 38$ \\
\hline 15 & Videoüberwachung & Daily news & $\begin{array}{l}\text { Brandenburg } \\
\text { Aktuell }\end{array}$ & ORB & 26.8 .00 & $19: 30$ & $3: 08$ & $0: 59: 51$ \\
\hline 16 & $\begin{array}{l}\text { Bericht des } \\
\text { Datenschutzbeauftragten }\end{array}$ & Daily news & $\begin{array}{l}\text { Brandenburg } \\
\text { Aktuell }\end{array}$ & ORB & 5.3 .01 & $19: 30 ?$ & $2: 20$ & $1: 03: 00$ \\
\hline 17 & Videoüberwachung & Daily news & $\begin{array}{l}\text { Brandenburg } \\
\text { Aktuell }\end{array}$ & ORB & 4.4 .01 & $19: 30$ & $2: 25$ & $1: 05: 39$ \\
\hline
\end{tabular}


Bavaria

\begin{tabular}{|l|l|l|l|l|l|l|l|l|}
\hline No. & Title & $\begin{array}{l}\text { Fomat of } \\
\text { the } \\
\text { broadcas } \\
\mathbf{t}\end{array}$ & Program title & Network & Date & Time & $\begin{array}{l}\text { Duratio } \\
\mathbf{n}\end{array}$ & Video \\
\hline 18 & $\begin{array}{l}\text { Ganovenjagd contra } \\
\text { Datenschutz }\end{array}$ & $\begin{array}{l}\text { Political } \\
\text { report }\end{array}$ & Zeitenspiegel & BR & 3.9 .00 & $21: 21$ & $5: 13$ & $0: 03: 55$ \\
\hline 19 & $\begin{array}{l}\text { Videoüberwachung } \\
\text { öffentlicher Plätze }\end{array}$ & $\begin{array}{l}\text { Daily } \\
\text { news }\end{array}$ & Abendschau & BR & 30.4 .01 & $17: 45$ & $2: 27$ & $0: 09: 22$ \\
\hline 20 & $\begin{array}{l}\text { Videoüberwa hung } \\
\text { Schily contra } \\
\text { Beckstein }\end{array}$ & $\begin{array}{l}\text { Week in } \\
\text { review }\end{array}$ & Ba yemzeit & BR & 26.5 .01 & $17: 30$ & $3: 05$ & $0: 14: 00$ \\
\hline 21 & $\begin{array}{l}\text { Spanien: der Intemet- } \\
\text { Kindergarten }\end{array}$ & $\begin{array}{l}\text { Political } \\
\text { report }\end{array}$ & Wir in Europa & BR & 3.6 .01 & $17: 30$ & $3: 45$ & $0: 00: 00$ \\
\hline 22 & $\begin{array}{l}\text { Videoüberwachung } \\
\text { (England) }\end{array}$ & $\begin{array}{l}\text { Political } \\
\text { report }\end{array}$ & Gla sklar & BR & 18.9 .01 & $21: 20$ & $2: 02$ & $0: 11: 55$ \\
\hline
\end{tabular}

